\title{
Normal modes of a coupled ice-shelf/sub-ice-shelf cavity system
}

\author{
Olga V. SERGIENKO \\ Atmospheric and Oceanic Sciences Program, Princeton University/Geophysical Fluid Dynamics Laboratory, \\ Princeton, NJ, USA \\ E-mail: osergien@princeton.edu
}

\begin{abstract}
Ice shelves and ice tongues are dynamically coupled to their cavities. Here we compute normal modes (eigenfrequencies and eigenfunctions) of this coupled system using a thin-plate approximation for the ice shelf and potential water flow in the ice-shelf cavity. Our results show that normal modes depend not only on the ice-shelf parameters (length, thickness, Young's modulus, etc.) but also on the cavity depth. The dominant eigenmodes are higher for ice shelves floating over deeper cavities; they are also higher for shorter ice shelves and ice tongues $(<50 \mathrm{~km} \mathrm{long})$. The higheigenfrequency eigenmodes are primarily controlled by the ice flexure and have similar periods to sea swell. These results suggest that both long ocean waves with periods of $100-400 \mathrm{~s}$ and shorter sea swell with periods of 10-20 s can have strong impacts on relatively short ice shelves and ice tongues by exciting oscillations with their eigenfrequencies, which can lead to iceberg calving and, in some circumstances, ice-shelf disintegration.
\end{abstract}

\section{INTRODUCTION}

A growing body of observations of the ocean wave effects on ice shelves and ice tongues (e.g. MacAyeal and others, 2006; Cathles and others, 2009; Bromirski and others, 2010; Brunt and others, 2011) has revived interest in various aspects of ice-shelf/wave interaction. In the late 1970s/early 1980s Holdsworth and Glynn $(1978,1981)$ proposed that iceberg calving from ice tongues can be a result of ice-shelf vibration excited by ocean swell. Such vibration, especially with frequencies close to those of the ice-shelf normal modes (eigenfrequencies), can persist and cause significant flexural stresses, leading to ice-shelf fracturing and calving. Considering the effects of monochromatic long waves on the ice stress regime, Sergienko (2010) demonstrated that waveinduced flexural stresses are sufficiently large that, when superimposed on other existing stresses, they can lead to fracture initiation and development. Holdsworth and Glynn $(1978,1981)$ used numerical models to compute normal modes of a two-dimensional (plan view) ice tongue floating on inviscid water. In this study, similar to many other studies of ice-shelf flexure (e.g. Reeh, 1968; Vaughan, 1995), a one-dimensional ice shelf (or ice tongue) is considered, and analytical expressions for their normal modes are derived.

\section{GEOMETRY AND MODELS}

We consider an ice shelf or ice tongue with constant thickness, $H$, floating on inviscid sea water of depth $H_{c}$ (Fig. 1). It is assumed for the purpose of computing normal modes that there are no variations in the transverse direction, i.e. the plane-strain approximation is adopted. As in previous studies, floating ice is treated as elastic material with a constitutive relation described by Hooke's law. This choice is justified by the fact that the anticipated period of oscillations (seconds to hours) is short compared with the Maxwell time, which is defined to be the characteristic time required to create significant viscous deformations after an initial elastic deformation (Maxwell, 1867).

\section{Ice flexure}

The thin-beam approximation is used in the treatment of floating-ice flexure (e.g. Timoshenko and Goodier, 1934). The main reason for employing this approximation in the computation of the normal modes of an ice shelf and its cavity is the small aspect ratio (ice thickness or cavity depth to the ice-shelf length) of this system. The thinbeam approximation is based on the following assumptions: (1) there is a neutral plane at the mid-plane of the ice that does not experience deformation; (2) vertical shear stresses are negligible; and (3) vertical cross sections in the ice that are parallel when the ice is undeformed remain parallel when the ice is deformed. These assumptions allow simplifications in the momentum-balance equations describing the ice stress regime, and vertical integration of these equations. The wellknown thin-beam equation describing flexure of an elastic beam floating in inviscid water is

$$
\rho_{\mathrm{i}} H \frac{\partial^{2} \eta}{\partial t^{2}}=-\frac{\partial^{2}}{\partial x^{2}}\left(D \frac{\partial^{2} \eta}{\partial x^{2}}\right)-\rho_{\mathrm{w}} g \eta+P_{\mathrm{w}}
$$

where $\eta$ is the vertical displacement of the neutral plane, $\rho_{\mathrm{i}}$ is the ice density, $\rho_{\mathrm{w}}$ is the water density, $g$ is the acceleration due to gravity, $P_{\mathrm{w}}$ is the wave-induced pressure (described below), and $D$ is the effective flexural rigidity

$$
D=\frac{E H^{3}}{12\left(1-\nu^{2}\right)^{\prime}}
$$

where $E$ is the Young's modulus and $\nu$ the Poisson ratio.

In circumstances where $H(x)$ is spatially uniform, as in the present study, Eqn (1) can be rewritten as

$$
\rho_{\mathrm{i}} H \frac{\partial^{2} \eta}{\partial t^{2}}=-D \frac{\partial^{4} \eta}{\partial x^{4}}-\rho_{\mathrm{w}} g \eta+P_{\mathrm{w}}
$$

\section{Water flow}

Following common practice in studies of wave interactions with sea ice (e.g. Squire, 2007), sea water in the sub-ice-shelf cavity is assumed inviscid and irrotational. Its velocity can be described by a potential, $\Phi$,

$$
\vec{v}=\vec{\nabla} \Phi,
$$


where $\vec{v}$ is sea-water velocity. We use the shallow-water approximation (e.g. Stoker, 1957) to describe waves in the ice-shelf cavity. This approximation is justified by the fact that the aspect ratio of sub-ice-shelf cavities is small. The governing equation for $\Phi$ in the sub-ice-shelf cavity is

$$
\frac{\partial \eta}{\partial t}=-H_{\mathrm{c}} \frac{\partial^{2} \Phi}{\partial x^{2}}
$$

A detailed derivation of this equation is given by Stoker (1957). In a linear theory, the wave-induced pressure felt by the ice shelf, $P_{\mathrm{w}}$, is

$$
P_{\mathrm{w}}=-\rho_{\mathrm{w}} \frac{\partial \Phi}{\partial t} .
$$

Flexural waves of the ice-shelf/sub-ice-shelf cavity system are described by Eqns (3), (5) and (6) and the corresponding boundary conditions described below. It is useful to write these equations again:

$$
\begin{aligned}
\rho_{\mathrm{i}} H \frac{\partial^{2} \eta}{\partial t^{2}} & =-D \frac{\partial^{4} \eta}{\partial x^{4}}-\rho_{\mathrm{w}} \frac{\partial \Phi}{\partial t}-\rho_{\mathrm{w}} g \eta \\
\frac{\partial \eta}{\partial t} & =-H_{C} \frac{\partial^{2} \Phi}{\partial x^{2}},
\end{aligned}
$$

where the expression for $P_{\mathrm{w}}$ (Eqn (6)) was taken into account. The two models used in this study are similar to those used by Vinogradov and Holdsworth (1985) to study ocean-wave effects on an ice-tongue stress regime and to investigate their dependence on the length of the ice tongue.

It should be noted that many glaciological studies disregard the coupling effect of the ice shelf and sea water underneath it (last one or two terms in Eqn (7a)), and prescribe an arbitrary motion of sea water in the cavity (e.g. Bassis and others, 2008; Lescarmontier and others, 2012). Such treatments are justifiable in circumstances where the primary interest is the effect of tides. In studies focused on the effects of waves with shorter wavelengths, the coupling needs to be taken into account, because the ice-shelf flexure excites waves in the cavity (Sergienko, 2010).

\section{NORMAL MODES}

The system of equations describing flexural interaction of the ice shelf with water underneath is Eqns (7). These equations are complemented by the following set of boundary conditions. We assume that the ice shelf is clamped at the grounding line (boundary 1 in Fig. 1)

$$
\begin{aligned}
\eta & =0 \\
\frac{\partial \eta}{\partial x} & =0 .
\end{aligned}
$$

At the ice front (boundary 2 in Fig. 1) the following conditions are satisfied

$$
\begin{gathered}
\frac{\partial^{2} \eta}{\partial x^{2}}=0 \\
\frac{\partial^{3} \eta}{\partial x^{3}}=0 .
\end{gathered}
$$

These conditions correspond to zero normal stress and bending moment at the ice front. The boundary condition for $\Phi$ at the grounding line (boundary 3 in Fig. 1) is

$$
\frac{\partial \Phi}{\partial x}=0 .
$$

Since normal-mode oscillations are standing waves, there is no mass transport associated with them. Therefore, the

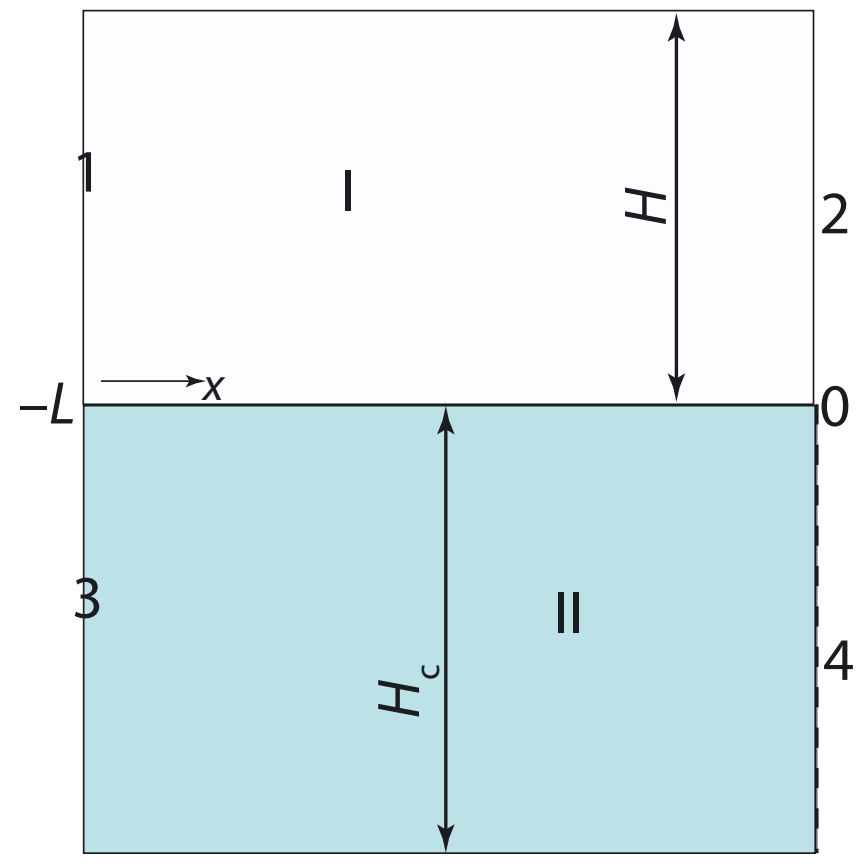

Fig. 1. Model geometry. I. ice-shelf domain; II. ocean domain. Conditions on boundaries 1-4 are described in the text.

boundary condition operating on the water layer at the ice front (boundary 4 in Fig. 1) is the no-flux condition, i.e.

$$
\frac{\partial \Phi}{\partial x}=0
$$

The variable $\eta$ can be eliminated from the above equations by differentiating Eqn ( $7 \mathrm{a}$ ) with respect to $t$ and substituting Eqn (7b). This yields a single equation for $\Phi$ :

$\rho_{\mathrm{i}} H H_{\mathrm{c}} \frac{\partial^{4} \Phi}{\partial t^{2} \partial x^{2}}-\rho_{\mathrm{w}} \frac{\partial^{2} \Phi}{\partial t^{2}}+D H_{\mathrm{c}} \frac{\partial^{6} \Phi}{\partial x^{6}}+\rho_{\mathrm{w}} g H_{\mathrm{c}} \frac{\partial^{2} \Phi}{\partial x^{2}}=0$.

Using separation of variables,

$$
\Phi(x, t)=X(x) T(t),
$$

we arrive at

$$
\frac{\rho_{\mathrm{i}} H}{D} \frac{\mathrm{d}^{2} T}{\mathrm{~d} t^{2}} \frac{\mathrm{d}^{2} X}{\mathrm{~d} x^{2}}-\frac{\rho_{\mathrm{w}}}{D H_{\mathrm{c}}} \frac{\mathrm{d}^{2} T}{\mathrm{~d} t^{2}} X+T \frac{\mathrm{d}^{6} X}{\mathrm{~d} x^{6}}+\frac{\rho_{\mathrm{w}} g}{D} T \frac{\mathrm{d}^{2} X}{\mathrm{~d} x^{2}}=0 .
$$

The above equation can be reduced to one involving $T(t)$ only,

$$
\frac{\mathrm{d}^{2} T}{\mathrm{~d} t^{2}}+\omega^{2} T=0,
$$

where $\omega$ is the eigenfrequency, if $X(x)$ satisfies the equation

$$
\frac{\mathrm{d}^{6} X}{\mathrm{~d} x^{6}}+\frac{\mathrm{d}^{2} X}{\mathrm{~d} x^{2}}\left(\frac{\rho_{\mathrm{w}} g}{D}-\omega^{2} \frac{\rho_{\mathrm{i}} H}{D}\right)+\omega^{2} \frac{\rho_{\mathrm{w}}}{D H_{\mathrm{c}}} X=0
$$

and boundary conditions

$$
\frac{\mathrm{d} X}{\mathrm{~d} x}=\frac{\mathrm{d}^{2} X}{\mathrm{~d} x^{2}}=\frac{\mathrm{d}^{3} X}{\mathrm{~d} x^{3}}=0, \quad x=-L
$$

at the landward terminus of the sub-ice ocean cavity, and

$$
\frac{\mathrm{d} X}{\mathrm{~d} x}=\frac{\mathrm{d}^{4} X}{\mathrm{~d} x^{4}}=\frac{\mathrm{d}^{5} X}{\mathrm{~d} x^{5}}=0, \quad x=0
$$

at the ice front. 
The general solution of Eqn (16) is

$$
\begin{aligned}
X(x)= & C_{1} \cos (\alpha x)+C_{2} \sin (\alpha x) \\
& +C_{3} \cos \left(\frac{1}{2} \alpha x\right) \cosh \left(\frac{\sqrt{3}}{2} \alpha x\right) \\
& +C_{4} \cos \left(\frac{1}{2} \alpha x\right) \sinh \left(\frac{\sqrt{3}}{2} \alpha x\right) \\
& +C_{5} \sin \left(\frac{1}{2} \alpha x\right) \cosh \left(\frac{\sqrt{3}}{2} \alpha x\right) \\
& +C_{6} \sin \left(\frac{1}{2} \alpha x\right) \sinh \left(\frac{\sqrt{3}}{2} \alpha x\right),
\end{aligned}
$$

where $C_{1}-C_{6}$ are unknown constants and

$$
\begin{aligned}
\alpha & =\sqrt{\frac{p}{3 u}-u} \\
u & =\left(-\frac{q}{2}+\sqrt{\frac{p^{3}}{27}+\frac{q^{4}}{4}}\right)^{\frac{1}{3}} \\
p(\omega) & =\frac{\rho_{\mathrm{w}} g}{D}-\omega^{2} \frac{\rho_{\mathrm{i}} H}{D} \\
q(\omega) & =\omega^{2} \frac{\rho_{\mathrm{w}}}{D H_{\mathrm{C}}} .
\end{aligned}
$$

Substitution of $X(x)$ in the form of Eqn (16) into boundary conditions, Eqns (17-18), leads to a system of homogeneous linear equations for $C_{1}-C_{6}$. This system has a nontrivial solution if its determinant is zero. Equating the determinant to zero generates a transcendental equation used to determine the eigenvalues, $\alpha$,

$$
\begin{aligned}
& 4 \cosh \left(\frac{\sqrt{3}}{2} \gamma\right) \sin \left(\frac{\gamma}{2}\right)+\sin (\gamma)[4+\cosh (\sqrt{3} \gamma)]+\sin (2 \gamma) \\
& =4 \sqrt{3} \sinh \left(\frac{\sqrt{3}}{2} \gamma\right) \cos \left(\frac{\gamma}{2}\right)+\sqrt{3} \sinh (\sqrt{3} \gamma) \cos (\gamma),
\end{aligned}
$$

where $\gamma=\alpha L$. Roots of this equation are found numerically. The first three nonzero roots of Eqn $(24)$ are $\gamma_{1} \approx 4.2747$, $\gamma_{2} \approx 7.3268$ and $\gamma_{3} \approx 10.4716$. For $n>3$ the roots of this equation can be approximated as

$$
\gamma_{n} \approx \pi\left(n+\frac{1}{3}\right)
$$

Eigenvalues, $\alpha_{n}$, of Eqn (16) are

$$
\alpha_{n}=\frac{\gamma_{n}}{L} .
$$

Equation (24) also has a trivial root, $\gamma=0$. It corresponds to no motion in the system.

The expression for eigenfrequencies, $\omega_{n}$, is determined from Eqn (20), and can be written as

$$
\frac{p\left(\omega_{n}\right)}{3 u\left(\omega_{n}\right)}-u\left(\omega_{n}\right)=\alpha_{n}^{2}
$$

where $u_{n}$ depends on $\omega_{n}$ through Eqns (22) and (23). Equation (27) is a dispersion relationship written in an implicit form. The eigenfrequencies, $\omega_{n}$, corresponding to eigenvalues $\alpha_{n}$ are the roots of this expression, and they are found numerically.

The corresponding eigenfunctions of $\Phi_{n}$ are

$$
\Phi_{n}(x, t)=X_{n}(x) \exp \left(i \omega_{n} t\right) \text {. }
$$

The expressions for $\eta_{n}$ eigenfunctions are determined from Eqn (7b).
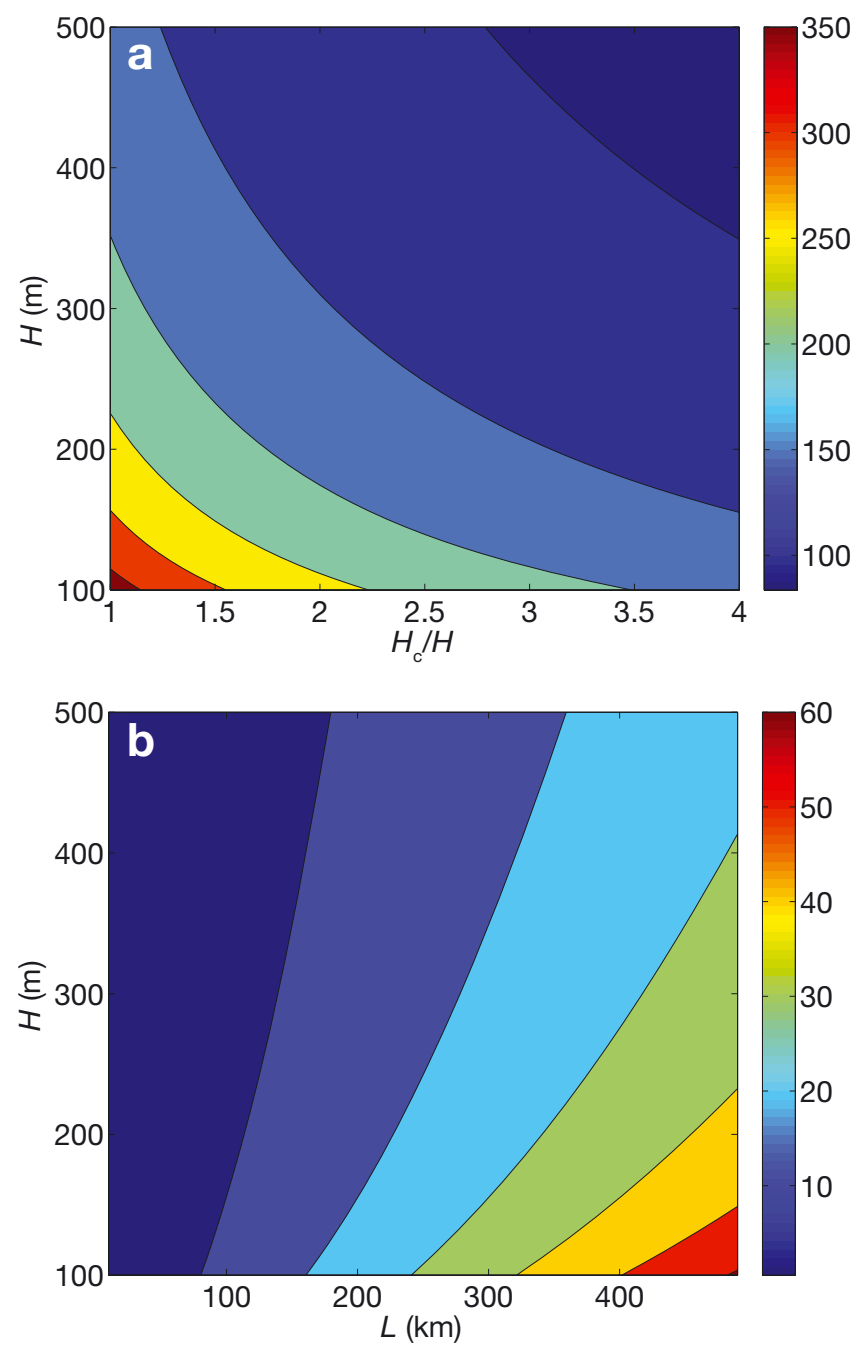

Fig. 2. Period of the first, most fundamental normal modes of various ice shelves. (a) $50 \mathrm{~km}$ long and various ice thicknesses and cavity depths, period $T$ (sec); (b) various lengths but with cavity depth equal to the ice thickness, period $T$ (min). Note the difference in the period units between (a) and (b).

\section{DISCUSSION AND CONCLUSIONS}

Figure 2 shows the first, most fundamental, normal modes of a variety of ice shelves with various geometries. Ice shelves with deeper cavities generally have shorter normal-mode periods. Ice shelves $<100 \mathrm{~km}$ long with cavity depths larger than their thicknesses generally have periods of the first normal mode in the range 100-200 s. Longer ice shelves have longer normal-mode periods (e.g. the normal-mode period of a $100 \mathrm{~km}$ long and $200 \mathrm{~m}$ thick ice shelf above a 200 m deep cavity is $\sim 20 \mathrm{~min}$ ).

For higher modes the ice-shelf-flexure effects rapidly increase and shift the normal modes of the coupled system to frequencies higher than they would have been without ice-shelf flexure. As Figure 3a shows, higher normal modes are less sensitive to the depth of the cavity. However, their dependence on the ice-shelf length is similar to the lower modes (Fig. 3b). These results suggest that different floating tongues that usually have length $\sim 10-15 \mathrm{~km}$ will respond in a similar way to sea swell, regardless of the water depth underneath them. It is feasible that the uniform length of ice tongues can be explained by their natural oscillations and by the fact that their higher frequencies are primarily 

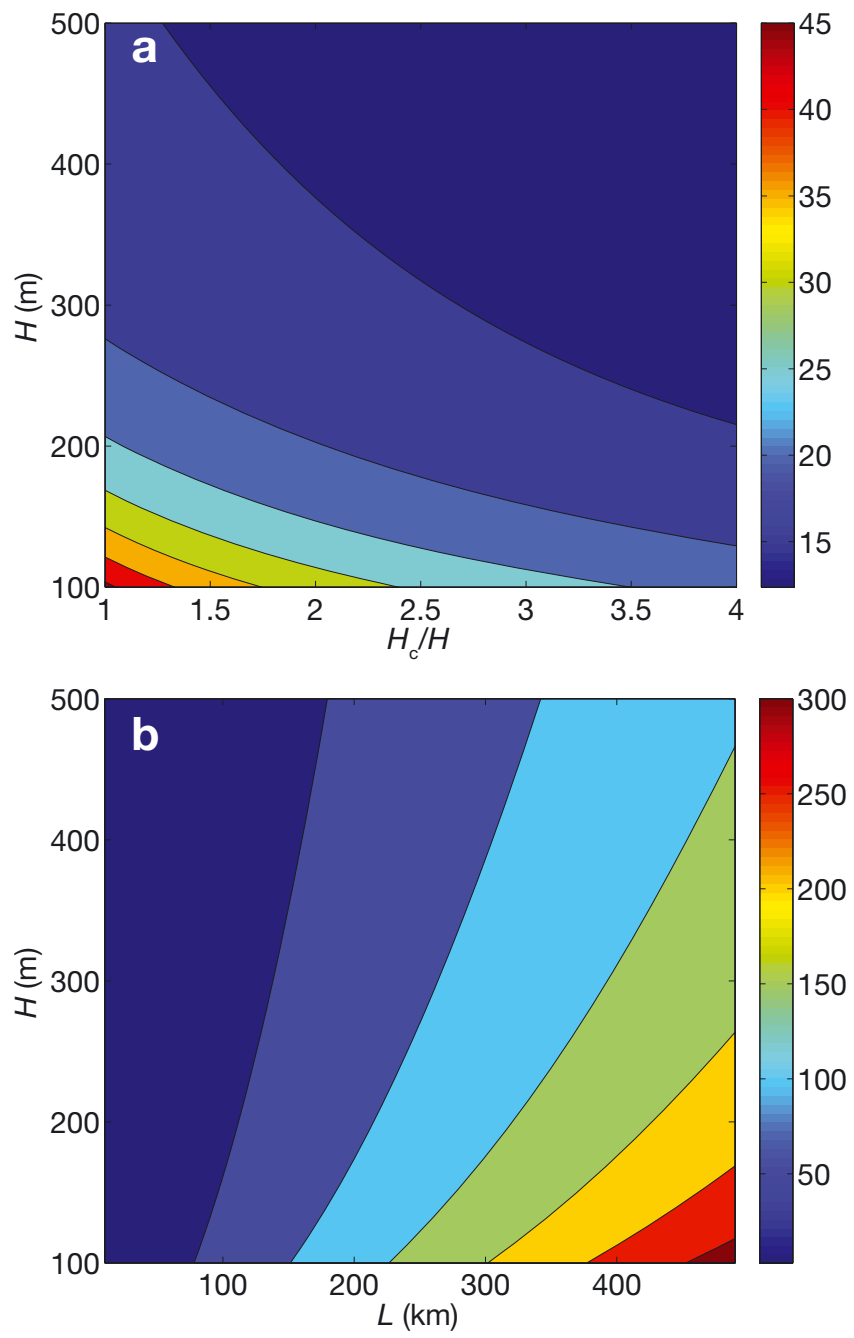

Fig. 3. Same as Figure 2 for the 15th normal mode. Periods are in seconds.

determined by ice flexure, and less dependent on the cavity or other aspects of ocean geometry.

The eigenfrequencies increase (eigenperiods decrease) rapidly as the modes increase. Figure 4 shows eigenperiods of an ice shelf $300 \mathrm{~m}$ thick, $50 \mathrm{~km}$ long with cavity depth $300 \mathrm{~m}$. The periods of the 10th and 15th modes are $\sim 25 \mathrm{~s}$ and $\sim 12 \mathrm{~s}$, respectively. These periods correspond to sea swell that is common around the Antarctic coast during the austral summer (e.g. Cathles and others, 2009). Hence, oscillations corresponding to 10-20 normal modes are likely to be excited.

A crucial question in the analysis of wave influences on ice shelves is whether waves in the open ocean can excite motions of the ice shelf that lead to the ice-shelf flexural stresses. Here the presented computation of normal modes of floating ice shelves demonstrates that for relatively short ice shelves or floating glaciers $(\leq 50 \mathrm{~km})$ the first, most fundamental, normal mode is in the 100-400 s period range, with higher-order modes following at shorter periods. This means that both long ocean waves with periodicities $\geq 200 \mathrm{~s}$, and shorter waves with periodicities 10-20s are likely to couple well with ice shelves and lead to significant stress effects, leading to iceberg calving (Holdsworth and Glynn, 1978). The long-period waves are formed as a result of nonlinear interaction of waves with shorter wavelength,

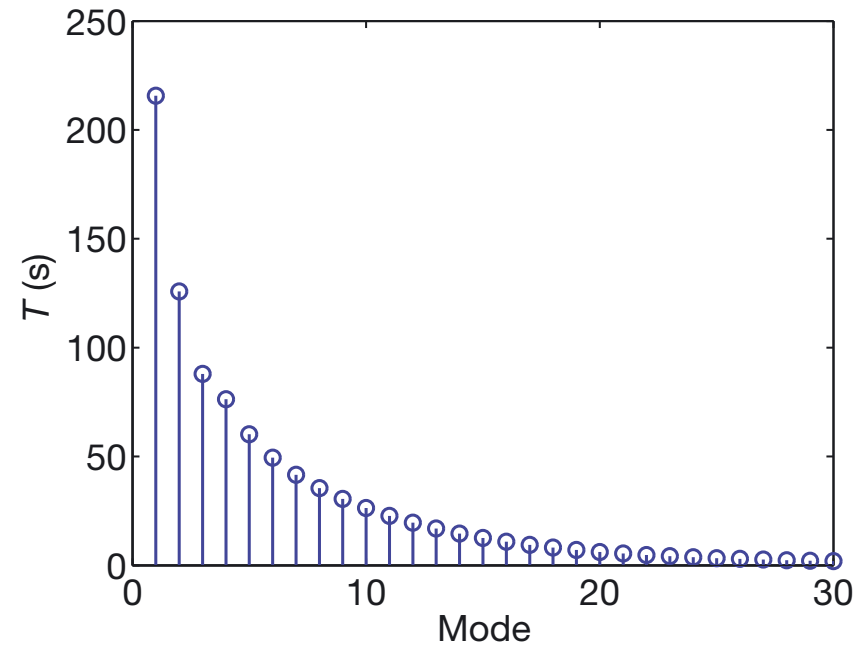

Fig. 4. Periods of the normal modes of an ice shelf $300 \mathrm{~m}$ thick, $50 \mathrm{~km}$ long with a cavity $300 \mathrm{~m}$ deep.

and can be either created locally or travel from afar (e.g. Bromirski and others, 2010), and the wave energy in the seaswell spectrum is abundant around Antarctica (e.g. NOAA WAVEWATCH, 2010). Therefore, short ice shelves and ice tongues are most susceptible to the mechanical effects of the ice/ocean interaction.

Another aspect that plays an important role, but is not considered in this study, is wave dissipation. Caused by turbulent processes and interaction with bottom topography, it tends to reduce the wave amplitudes as they propagate into the ice-shelf cavity. The reinforcement of wave propagation mentioned above, due to ice-shelf flexure, counteracts the effects of dissipation to some degree, and is most effective closer to the ice front, where calving occurs and observed ice-shelf disintegrations initiate. However, in order to excite significant flexural stresses, ocean waves have to have high amplitudes to overcome dissipation. Perhaps the relatively rare occurrence (so far) of very strong storms (e.g. Shillington, 1981) explains why ice-shelf disintegrations are also relatively rare.

\section{ACKNOWLEDGEMENTS}

I am indebted to Caroline Muller for catching an error in the original analysis. I thank Doug MacAyeal and Chief Editor Jo Jacka for help with the manuscript. Valuable comments and constructive criticisms by two anonymous referees are gratefully acknowledged. This research is supported by US National Science Foundation grants ANT-0838811 and ARC-0934534.

\section{REFERENCES}

Bassis JN, Fricker HA, Coleman R and Minster J-B (2008) An investigation into the forces that drive ice-shelf rift propagation on the Amery Ice Shelf, East Antarctica. J. Glaciol., 54(184), 17-27 (doi: 10.3189/002214308784409116)

Bromirski PD, Sergienko OV and MacAyeal DR (2010) Transoceanic infragravity waves impacting Antarctic ice shelves. Geophys. Res. Lett., 37(L2), L02502 (doi: 10.1029/2009GL041488)

Brunt KM, Okal EA and MacAyeal DR (2011) Antarctic ice-shelf calving triggered by the Honshu (Japan) earthquake and tsunami, 
March 2011. J. Glaciol., 57(205), 785-788 (doi: 10.3189/ 002214311798043681 )

Cathles LM, Okal EA and MacAyeal DR (2009) Seismic observations of sea swell on the floating Ross Ice Shelf, Antarctica. J. Geophys. Res., 114(F2), F02015 (doi: 10.1029/ 2007JF000934)

Holdsworth G and Glynn JE (1978) Iceberg calving from floating glaciers by a vibrating mechanism. Nature, 274(5670), 464-466 (doi: 10.1038/274464a0)

Holdsworth G and Glynn JE (1981) A mechanism for the formation of large icebergs. J. Geophys. Res., 86(C4), 3210-3222 (doi: 10.1029/JC086iC04p03210)

Lescarmontier L, Legrésy B, Coleman R, Perosanz F, Mayet C and Testut L (2012) Vibrations of Mertz Glacier ice tongue, East Antarctica. J. Glaciol., 58(210), 665-676 (doi: 10.3189/ 2012JoG11J089)

MacAyeal DR and 13 others (2006) Transoceanic wave propagation links iceberg calving margins of Antarctica with storms in tropics and Northern Hemisphere. Geophys. Res. Lett., 33(17), L17502 (doi: 10.1029/2006GL027235)

Maxwell JC (1867) On the dynamical theory of gases. Phil. Trans. R. Soc. Lond., 157, 49-88 (doi: 10.1098/rstl.1867.0004)
NOAA WAVEWATCH IIITM (2010) National Oceanic and Atmospheric Administration National Weather Service. http://www. oceanweather.com/data/

Reeh N (1968) On the calving of ice from floating glaciers and ice shelves. J. Glaciol., 7(50), 215-232

Sergienko OV (2010) Elastic response of floating glacier ice to impact of long-period ocean waves. J. Geophys. Res., 115(F4), F04028 (doi: 10.1029/2010JF001721)

Shillington FA (1981) Low frequency $0.045-\mathrm{Hz}$ swell from the Southern Ocean. Nature, 290(5802), 123-125 (doi: 10.1038/ 290123a0)

Squire VA (2007) Of ocean waves and sea-ice revisited. Cold Reg. Sci. Technol., 49(2), 110-133 (doi: 10.1016/j.coldregions. 2007.04.007)

Stoker JJ (1957) Water waves: the mathematical theory with applications. Wiley Interscience, New York

Timoshenko SP and Goodier JN (1934) Theory of elasticity. McGraw-Hill, New York

Vaughan DG (1995) Tidal flexure at ice shelf margins. J. Geophys. Res., 100(B4), 6213-6224 (doi: 10.1029/94JB02467)

Vinogradov OG and Holdsworth GH (1985) Oscillation of a floating glacier tongue. Cold Reg. Sci. Technol., 10(3), 263-271

MS received 13 May 2012 and accepted in revised form 13 September 2012 